\title{
EMPREGO E TRABALHO NO INÍCIO DO SÉCULO XXI: revisitando Keynes e Marx
}

\author{
Benedito Rodrigues de Moraes Neto*
}

\begin{abstract}
A natureza do trabalho nas economias avançadas apresentou significativa mudança recente. O progresso tecnológico ocasionou redução do trabalho sem conteúdo e ampliação daquele de maior qualificação ou escolaridade, fenômeno para cuja discussão se busca auxílio de Keynes e Marx. No caso de Keynes, destaca-se sua antevisão de que o progresso tecnológico geraria imensa redução do tempo de trabalho e ampliação do tempo de lazer. Considerando que isso não ocorreu, a falha pode ter acontecido por trabalhar com oposição entre trabalho sem conteúdo e lazer, não possibilitando capturar as mudanças históricas no trabalho e na relação dos homens com ele. A visão de Marx é completamente diferente, pois sua oposição se dá entre trabalho desprovido de conteúdo e "trabalho atividade", esse último impregnado de conteúdo e fundamental para o desenvolvimento das individualidades. A realidade atual tem, portanto, uma maior "colagem” com Marx e apresenta grandes desafios para o capitalismo e sua crítica. PALAVRAS-chave: Keynes. Marx. Emprego. Trabalho. Progresso técnico.
\end{abstract}

Em tempos de forte crise, é grande o desafio de pensar a questão do emprego e do trabalho numa perspectiva mais tendencial, mais históricoestrutural. Paradoxalmente, a inspiração para isso vem de Keynes, o maior dos teóricos sobre a crise e seus remédios, que, em curto ensaio escrito em 1930, no "olho do furacão" da maior crise do capitalismo, debruçou-se sobre a questão exatamente sob o ponto de vista do longo prazo. Utilizaremos esse ensaio, sugestivamente intitulado "Economic Possibilities for our Grandchildren” (Keynes, 2008), como ponto de partida, explicitando inicialmente suas duas principais colocações:

a) Num primeiro momento, o progresso tecnológico criaria um novo tipo de desemprego, denominado "desemprego tecnológico", devido ao fato de que esse progresso ocorreria num ritmo mais elevado do que a capacidade da sociedade de absorver trabalhadores.

\footnotetext{
* Doutor em Ciências Econômicas. Professor adjunto (livre-docente) aposentado do Departamento de Economia da UNESP em Araraquara, SP.

Rodovia Araraquara-Jaú, km 1. Cep: 14800-901. Araraquara - São Paulo - Brasil. brmneto@gmail.com
}

b) Todavia, o problema acima se deveria apenas a uma "temporária fase de desajustamento". O fundamental, para Keynes, é que, no longo prazo, em função do progresso tecnológico, a humanidade conseguiria resolver em definitivo o "problema econômico", consistente na "luta pela subsistência". Isso permitiria uma vigorosa redução do tempo dedicado ao trabalho: "Turnos de três horas, ou uma semana de trabalho de quinze horas, poderiam resolver em grande medida o problema." (2008, p. 23) Todo o restante do tempo seria dedicado a pequenas tarefas domésticas e, em especial, ao lazer.

Em coletânea recente, inteiramente dedicada ao curto ensaio de Keynes (Pecchi; Piga, 2008), os diversos autores procuram elementos para entender como o grande economista pôde ser, a um só tempo, extremamente percuciente, em especial naquele momento da história, na antevisão da tendência ao progresso tecnológico sob o capitalismo, e tão equivocado com respeito à redução do tempo dedicado ao trabalho. Ainda que a jornada semanal de trabalho das pessoas efetivamente empregadas tenha, na verdade, se reduzido bastante ao 
longo da maior parte do século XX, ela se estabilizou mais para o fim desse século em um nível bem mais elevado do que o antevisto por Keynes: como nos informa Freeman, em 2005 ela chegou à média de 34,7 horas semanais nos Estados Unidos e 27,6 horas na Alemanha (Freeman, 2008, p.142, nota 2). Um aspecto do debate realizado na coletânea nos interessa particularmente: o de que Keynes teria chegado a essa antevisão por forte influência de Marx, que teria sobre o trabalho uma visão análoga à da Escola Neoclássica da Economia. Vejamos as observações nesse sentido:

O mais surpreendente do tratamento dado ao trabalho por Keynes em seu ensaio não é sua previsão incorreta de que rendas mais elevadas causariam uma queda vertiginosa no tempo de trabalho, mas sim sua visão depreciativa sobre todo o tipo de trabalho (Freeman, 2008, p. 139).

Minha forte crença é que esta específica predição de Keynes (de produzir tudo o que se necessita em muito menos horas de trabalho, dedicando, portanto, muito mais horas ao lazer) é guiada por uma crucial 'falácia antropológica'. A visão keynesiana do trabalho é extremamente influenciada pelo conceito marxista de alienação e estruturada sobre a perspectiva específica dos livros-texto de Economia acerca dos 'trabalhadores manuais'. [...] se olharmos para a maior parte das formalizações ou do pensamento teórico em Economia do Trabalho, e naquelas prevalecentes à época de Keynes, veremos que elas são bastante próximas da perspectiva marxista (qual seja, a de que trabalho é apenas alienação). O indivíduo escolhe a alocação ótima de suas horas entre trabalho e lazer. O trabalho não produz nenhuma satisfação e, em formalizações-padrão, é acompanhado por um custo imaterial representado pela desutilidade do esforço. Tal desutilidade, ou ausência de utilidade, é compensada por uma recompensa monetária (o salário), que é usada para o desfrute dos bens de consumo durante o tempo dedicado ao lazer. É claro, portanto, que, se nos aferrarmos a esta visão, a qual devemos entender como fortemente influenciada pela prevalência de tarefas alienadas à época de Keynes, devemos provavelmente esperar que o ‘alienado' homo oeconomicus deveria tentar explorar os incrementos na produtividade e nos salários por hora para reduzir as horas trabalhadas (Becchetti, 2008, p.187-188).

Teria sido essa excessiva influência marxista-neoclássica a responsável pela incapacidade demonstrada por Keynes de visualizar uma dimensão enriquecedora do trabalho, a qual se teria for- talecido em momentos mais recentes:

Uma atração pelo trabalho também ajuda a explicar porque a previsão de uma jornada de trabalho tão imensamente reduzida ficou tão longe da efetivamente alcançada [...] Muitas pessoas vão ao trabalho por razões que vão além do dinheiro, e podem preferir trabalhar mais do que as quinze horas por semana de Keynes sob quase qualquer circunstância (Freeman, 2008, p. 140). A falácia antropológica que afeta Keynes é a de considerar apenas o componente alienante do trabalho humano, sem considerar seu lado positivo, consistente na realização da dimensão criativa do ser humano (Becchetti, 2008, p. 188).

Keynes nunca visualizou que, junto com o progresso técnico e a intensificação do uso do capital, que ele postulou argutamente, uma parcela sempre crescente da população pode permitirse ter empregos estimulantes e atraentes. [...] Portanto, se a população em idade de trabalhar não trabalhar, ou trabalhar apenas umas poucas horas por semana, uma grande parte dela se verá privada de usufruir da maior recompensa oferecida pelas economias mais avançadas (Phelps, 2008, p. 102).

A falácia da visão antropológica do trabalho humano e a incapacidade de compreender a evolução dos empregos e das atividades criadoras de valor estão na raiz da equivocada noção de Keynes sobre o futuro das horas trabalhadas (Becchetti, 2008, p.189).

Antes de discutir criticamente a empobrecida visão de Becchetti sobre o trabalho em Marx, o que nos permitirá visualizar uma interessante analogia entre Keynes e Marx, vale considerar o que teria acontecido historicamente com o trabalho nas economias mais avançadas, como forma de avaliar a antevisão de Keynes e as observações acima sobre a razão de seu equívoco maior. Uma primeira observação é que a postulação da existência da "falácia antropológica" de Keynes só faz sentido num mundo pós-fordista. No mundo do taylorismofordismo, que teve grande presença na maior parte do século XX, a visão depreciativa de Keynes sobre o trabalho faz todo o sentido. Essa visão se ajusta plenamente, em nossos dias, ao trabalho nas megafábricas chinesas de montagem de produtos eletrônicos, sendo a famigerada cidade-fábrica da Foxconn em Shenzhen, com seus quase 400.000 trabalhadores, sua ilustração mais rica. As razões pelas quais o trabalho sob o taylorismo-fordismo merece toda a visão depreciativa de Keynes sobre 
o trabalho foram desenvolvidas por nós em vários ensaios (Moraes Neto, 1989, 2003, 2005, 2008). O que interessa marcar aqui é que, com o advento da automação de base microeletrônica (e não com o advento do toyotismo/ohnoísmo, como pensaram muitos), o taylorismo-fordismo morreu no mundo mais avançado, e foi deslocado, com grande força, para as franjas mais atrasadas do sistema econômico mundial. Apenas para marcar a distância dos dias atuais em relação à fase fordista, vale a seguinte lembrança:

Com um total de empregados de 60.400, a Apple possui menos de um quarto do número de empregados da quinquagésima empregadora segundo a revista Fortune, a AT\&T. Quando da morte do fundador da Apple, Steve Jobs, em 2011, vários comentadores o compararam a Henry Ford. Como inovadores e criadores de valor para os acionistas, os dois são na verdade comparáveis. Mas como empregadores eles não o são. Durante os anos 30, Ford empregava mais de cem mil pessoas numa única planta - o complexo River Rouge, em Michigan. E esta era apenas uma das muitas plantas de Ford nos Estados Unidos e fora dele (Noah, 2012, p.101-102).

A citação acima já nos coloca numa das principais características do pós-fordismo, qual seja, a grande diminuição do emprego na indústria, a qual, durante o período fordista, oferecia empregos de remuneração relativamente alta para trabalhadores de nível de qualificação ou escolaridade não elevado. Diversos autores têm enfatizado o peso que teve a indústria de bens de consumo duráveis, ou seja, o segmento taylorista-fordista da indústria, na oferta dessa grande quantidade de empregos bem remunerados e pouco exigentes de qualificação (Holzer; Lane; Rosenblum; Andersson, 2011, p. 7, 15). Éa partir da superação dessa fase que devemos procurar as razões da "falácia antropológica" keynesiana. A grande diminuição do emprego industrial, nos anos recentes, deve-se, no fundamental, a grandes avanços de ordem tecnológica, que deixaram para trás o taylorismo-fordismo, mudando radicalmente a natureza dos processos de trabalho:

Tecnologias como robótica, máquinas de controle numérico, controle computadorizado de esto- ques e transcrição automática têm substituído as tarefas rotineiras, desalojando os trabalhadores (Brynjolfson; McAfee, 2011, p.41).

[...] para os Estados Unidos como um todo, o comércio e o outsourcing explicam apenas $20 \%$ da perda de 5,8 milhões de empregos na indústria durante o período 2000-2010; mais de dois terços da perda de empregos pode ser atribuída ao contínuo crescimento da produtividade (McKinsey Global Institute, 2012, p. 8).

A grande mudança ocasionada pelo progresso tecnológico, a partir das duas últimas décadas do século XX, refletiu-se fortemente na estrutura das ocupações nas economias mais avançadas, com diminuição vigorosa das atividades de trabalho desprovidas de conteúdo, em todos os setores. Ainda que a preocupação keynesiana do "desemprego tecnológico" não mereça ser desprezada ${ }^{1}$, é a forte alteração nas exigências de qualificação para o trabalho, em todas as áreas de atividade, a mais marcante das alterações recentes no que se refere ao trabalho nas economias mais avançadas:

Portanto, nossa predição ao estilo de Simon é de que a maior consequência da computadorização não será o desemprego em massa, mas sim um contínuo declínio da demanda por trabalho moderadamente ou menos qualificado. As oportunidades de emprego irão crescer, mas o crescimento do emprego será maior nas ocupações de maior nível de qualificação, nas quais os computadores irão complementar o pensamento especializado (expert thinking) e a comunicação complexa (complex communication) para produzir novos produtos e serviços (Levy; Murnane, 2004, p. 152).

[...] o acréscimo na demanda relativa por trabalhadores qualificados está fortemente correlacionado com os avanços da tecnologia, particularmente as tecnologias digitais (Brynjolfsson; McAfee, 2011, p. 41).

Como temos visto, as forças do crescimento econômico causam agora uma demanda crescente por trabalhadores altamente qualificados, enquanto reduzem a demanda por trabalhadores menos qualificados. [...] Se nossa previsão está correta, essa tendência irá continuar, e os empre-

${ }^{1}$ Sobre esse ponto, vale citar Brynjolfsson e MacAfee: "A falta de empregos não é simplesmente uma questão de despedida em massa de trabalhadores em função da Grande Recessão. Ao invés disso, ela reflete profundas questões estruturais que têm piorado há uma década ou mais. O JOLTS (Bureau of Labor Statistics Job Openings and Labor Turnover Survey) mostra uma dramática queda nas contratações desde 2000. Falta de contratações, mais do que aumento nas despedidas, é o fator responsável pela maior parte da atual falta de empregos" (2011, p. 35). 
gos de tipo operário (blue-collar) e de apoio administrativo (clerical jobs) continuarão a desaparecer (Levy; Murnane, 2004, p. 153-155).

$\mathrm{O}$ capítulo conclui que, contrariamente à percepção popular, empregos relativamente bons não estão desaparecendo, mas eles estão menos disponíveis nas indústrias onde eles eram tradicionalmente encontrados (na produção de bens duráveis), e crescentemente requerem níveis mais elevados de educação e qualificação dos trabalhadores (Holzer; Lane; Rosenblum; Andersson, 2011, p. 15).

De maneira geral, os resultados por indústria nos contam uma história bastante consistente. Muitos empregos de salário elevado ainda estão disponíveis e estão sendo criados nos mercados de trabalho nos Estados Unidos. Todavia, é menos provável que antes encontrá-los na indústria; é mais provável achá-los numa grande variedade de serviços. Na verdade, é impressionante a magnitude das mudanças no emprego entre as atividades produtivas no período de aproximadamente uma década. E no interior da indústria, e em qualquer outro lugar, os empregos que permanecem estão se tornando menos acessíveis a trabalhadores que possuam fraca qualificação pessoal (Holzen; Lane; Rosenblum; Andersson, 2011, p. 43).

A sensível alteração na natureza das ocupações gerou um comentário significativo de Enrico Moretti em livro bastante recente:

Numa fábrica, os componentes dominantes do chão de fábrica são claramente as máquinas, e tudo o mais, incluindo a localização e as atividades das pessoas que as operam, ocorre em torno delas. Num laboratório ou numa empresa de software, são claramente as pessoas que importam, e tudo ocorre em torno delas. Ironicamente, os locais de trabalho onde são criadas as mais inovadoras tecnologias são ainda largamente dependentes do trabalho humano, enquanto os locais de trabalho onde são produzidos os bens tradicionais são amplamente tocados por robôs (Moretti, 2012, p. 63).

Um desdobramento relevante da mudança recente nas ocupações nos Estados Unidos, que estamos usando como referência fundamental, é que estão desaparecendo as diferenças anteriormente existentes entre a natureza dos trabalhos na indústria e nos serviços:

Debates acerca da importância da indústria versus serviços numa economia, por exemplo, ignoram o fato de que a linha divisória entre esses setores está borrada (McKinsey; Global Institute, 2012, p. 17).
Essa homogeneização do trabalho ocorre até mesmo no interior da atividade industrial, cada vez mais impregnada de atividades de trabalho típicas dos serviços:

Incluindo os serviços demandados de outros setores (outsourced services), encontramos que, nos Estados Unidos, os empregos relacionados a serviços na indústria agora excedem os empregos ligados à produção - 8,9 milhões em serviços versus 7,3 milhões na produção (McKinsey; Global Institute, 2012, p. 7).

Em função dessa unificação da natureza das atividades de trabalho, o fato de ele possuir ou não um resultado material perdeu qualquer relevância:

Ao final, não importa se os trabalhadores americanos produzam alguma coisa física ou alguma coisa imaterial. O que realmente interessa é que os trabalhadores norte-americanos produzam bens ou serviços que sejam inovadores e dificilmente reproduzíveis. Esta é a única maneira de gerar empregos de elevada remuneração em face da renhida competição global (Moretti, 2012, p. 55).

Já nos é possível, após as referências aos resultados das pesquisas empíricas mais recentes sobre o trabalho nas economias avançadas, em particular nos Estados Unidos, localizar com precisão aquilo que Becchetti denominou "falácia antropológica" presente na visão keynesiana sobre o trabalho no século XXI. De forma bastante abrupta, em função do progresso tecnológico observado desde o final do século XX, com destaque para a microeletrônica, observou-se uma tendência de eliminação, nas sociedades mais avançadas, daquelas atividades de trabalho esvaziadas de conteúdo, típicas do taylorismo-fordismo. Ademais do progresso tecnológico, a possibilidade de transferilas para as "franjas" do sistema econômico mundial, como as linhas de montagem para a China e os "call-centers" para a Índia, reforçaram aquela tendência de eliminação. As atividades de trabalho tornaram-se cada vez mais impregnadas de conteúdo, em todos os segmentos produtivos, e cada vez mais exigentes em termos de qualificação ou escolarização. Em função disso, pode-se entender que a relação das pessoas com suas atividades de trabalho tenham 
perdido a natureza de "estranhamento", e que o trabalho tenha sido crescentemente assumido como parte fundamental do desenvolvimento das individualidades. Os estudos recentes têm apontado exatamente nessa direção, enfatizando a importância de uma carreira para que se possa alcançar a autorrealização numa economia avançada (Phelps, 2008, p. 102). A razão pela qual Keynes não conseguiu antever tal processo histórico encontra-se fundamentalmente no fato de que ele encampou completamente a visão dos clássicos, especialmente neoclássicos, sobre o trabalho, de uma maneira geral, como uma canga a ser carregada com sofrimento pela espécie humana. Em função disso, o grande economista trabalhou sempre com a oposição entre "trabalho esvaziado de conteúdo, imanentemente alienado" e lazer. Veremos, mais à frente, que isso o diferencia fundamentalmente de Marx, exatamente ao contrário do que afirma Becchetti. Fica evidenciada, então, a razão do equívoco keynesiano: Por um lado, ele acertou completamente ao antever que o aumento da produtividade em função do progresso tecnológico teria como efeito de longo prazo a eliminação do trabalho esvaziado de conteúdo, cuja permanência ele caracterizava como a manifestação por excelência do "problema econômico". Por outro lado, ao se diminuir imensamente esse tipo de trabalho, o que sobraria às pessoas seria fundamentalmente o lazer, e ele não conseguiu visualizar a positividade que seria gerada a partir do próprio trabalho, como trabalho impregnado de conteúdo. É interessante lembrar que essa visão de Keynes significava que ele não se havia aprisionado ao taylorismo-fordismo, que, à sua época, já afirmava sua importância, dominando ramos significativos da indústria, em especial o metal-mecânico. Isso porque, se o aumento de produtividade fosse pensado por ele como advindo das inovações tayloristas-fordistas, não haveria como pensar, ao mesmo tempo, na tendência ao desaparecimento do "problema econômico". Nesse sentido, Keynes se alia a Marx, muito especialmente ao Marx dos Grundrisse, como veremos mais à frente. A grande diferença entre os dois está ligada à natureza da oposição: se Keynes trabalhava com a oposição entre "trabalho esvaziado de conteúdo" e lazer, a oposição, para Marx, se colocava entre "trabalho esvaziado de conteúdo" e "trabalho atividade".

Antes, porém, de dar destaque à diferença, énecessário esclarecer um aspecto comum aos dois autores: Keynes, como já mencionamos, e Marx passam ao largo do taylorismo-fordismo. No caso do segundo, se abstrairmos a impossibilidade histórica do encontro, certamente ele não teria considerado a linha de montagem taylorista-fordista como algo ancorado em uma grande máquina, a esteira transportadora, como quer Eleutério Prado (Prado, 2013, p. 25), mas sim como uma grande "máquina cujas peças são homens", como quis com grande acuidade Ferguson para o caso da manufatura (apud Marx, 1983, p. 284). O primeiro talvez tenha sido ajudado por uma determinação geográfica, pois o taylorismo-fordismo foi, acima de tudo, uma criação norte-americana e, no início da década de 30 do século XX, ainda não tinha se difundido para as nações europeias como ocorreu, ainda que com dificuldades e ajustes, no período pós-segunda guerra. De qualquer forma, independentemente das razões, Keynes manteve-se "colado" à grande contribuição de sua nação à história da tecnologia, ou seja, à máquina, tal como descrita agudamente por Marx em O Capital. De qualquer forma, foi a desconsideração do desvio mediocrizante das forças produtivas representadas pelo taylorismofordismo que permitiu aos dois grandes autores pensar no fim do trabalho esvaziado como resultado do progresso técnico. Ambos consideraram que a elevação da produtividade do trabalho não bastava para caracterizar com presteza os efeitos do progresso técnico; é necessário que essa elevação se dê em função da automação, ou seja, do desaparecimento do homem como instrumento de produção. É essa concepção que torna ambos tão atuais, tão pós-fordistas.

Após a consideração do que iguala os dois autores, voltemos ao que os diferencia, ou seja, a natureza da oposição que fundamenta o raciocínio. Já afirmamos que, diferentemente de Keynes, Marx trabalha com uma oposição entre "trabalho 
desprovido de conteúdo" e "trabalho atividade". A citação abaixo nos parece a mais importante para constatar este fato:

Trabalharás com o suor de teu rosto! foi a maldição que Jeová lançou a Adão, e é desta maneira, como maldição, que Adam Smith concebe o trabalho. O 'repouso' aparece como o estado adequado, como idêntico à 'liberdade' e à 'fortuna'. Parece estar muito longe de seu pensamento que o indivíduo, 'em seu estado normal de saúde, vigor, atividade, habilidade e destreza' tenha também a necessidade de sua porção normal de trabalho e da supressão do repouso. [...] Tem razão, sem dúvida, Adam Smith, na medida em que as formas históricas de trabalho - como trabalho escravo, servil, assalariado - sempre se apresentaram como trabalho forçado, imposto exteriormente, frente ao qual o não trabalho aparece como 'liberdade e fortuna'. Isto é duplamente verdadeiro: é verdadeiro com relação a este trabalho antitético ['quer dizer, condicionado por uma antítese de classe' (Rosdolsky, 1985, p.474)], e, em conexão com ele, ao trabalho para o qual ainda não se criaram as condições subjetivas e objetivas para que se torne trabalho atraente, autorrealização do indivíduo, o que de modo algum significa que seja mera diversão, mero entretenimento, como concebia Fourier. Precisamente, os trabalhos realmente livres, como, por exemplo, a composição musical, são ao mesmo tempo terrivelmente sérios e exigem o mais intenso dos esforços. O trabalho da produção material só pode adquirir esse caráter (de trabalho realmente livre, emancipado): 1) Se o seu conteúdo se tornar diretamente social; 2) Se se revestir de um caráter científico e surgir diretamente como tempo de trabalho geral. Por outras palavras, se deixar de ser o esforço do homem, simples força de trabalho natural no estado bruto, tendo sofrido um determinado treinamento, para se tornar a atividade do sujeito que regula todas as forças da natureza no seio do processo de produção (Marx, 1978, p. 119-120).

Observamos que Marx considera a visualização do trabalho a la Smith e Keynes, como algo a ser depreciado, que prejudica enormemente o desenvolvimento das individualidades, como ajustada apenas e tão somente ao caso de sua particular conformação pelas sociedades de classe. Por outro lado, de forma oposta a Keynes, considera o trabalho "livre e emancipado", "atraente", como momento fundamental da "autorrealização do indivíduo", ainda que possa exigir "o mais intenso dos esforços". Pode-se também inferir da citação que Marx considera o trabalho não ligado à reprodução material da sociedade, que ele ilustra com a composição musical, como aquele mais imediatamente apto a apresentar essas características positivas. Vemos, então, que a preocupação maior de Marx localiza-se na natureza do trabalho nas atividades voltadas à reprodução material da sociedade, objeto de suas conhecidas análises sobre a evolução dos processos de trabalho. Para o caso desse tipo de trabalho, são duas as condições postas para que ele se transforme em "trabalho livre e emancipado": uma de natureza social, a superação da forma social capitalista, e outra de natureza tecnológica, a transformação do processo de produção numa “aplicação tecnológica da ciência” (Marx, 1978, p. 221). Essa consideração nos leva para um momento fundamental da obra de Marx, que, a despeito de um momento de ambiguidade em $O$ Capital (Zilbersheid, 2000; Moraes Neto, 2004), tem a "abolição do trabalho" como passo crucial para a transcendência do modo de produção capitalista:

Apenas nesta fase (após a revolução) a autoatividade coincide com a vida material, o que corresponde à transformação dos indivíduos em indivíduos totais [...] a revolução comunista é dirigida contra o modo anterior de atividade, suprime o trabalho e supera a dominação de todas as classes ao superar as próprias classes (Marx; Engels, 1991, p. 108).

Em outro texto, trabalhamos a questão da evolução das forças produtivas dentro do capitalismo como elemento necessário para a conquista da “abolição do trabalho", através da generalização do "grande autômata", ou seja, da eliminação do homem como instrumento de produção (Moraes Neto, 2004). O que nos interessa marcar aqui é que, para Marx, o desenvolvimento da sociedade humana exige que seja abolido todo o trabalho que não contribua decisivamente para a "autorrealização do indivíduo". Ora, como "a humanidade só se propõe as tarefas que pode resolver" (Marx, 1974, p.136), dever-se-ia buscar, no interior do próprio capitalismo, em sua evolução histórica, o próprio encaminhamento da "abolição do trabalho" e da afirmação do trabalho como atividade, algo "atra- 
ente”, “autorrealização do indivíduo”. Ora, é exatamente isso que vem ocorrendo nos países de economia mais avançada, conforme nos revelam as análises empíricas mais recentes. Esse fato foi capturado nas análises de Negri e outros (Negri; Hardt, 2001; Negri; Lazzarato, 2001), o que os levou ao conceito de "trabalho imaterial", bastante infeliz, pois admitem que ele se difunde por todas as atividades produtivas, independentemente de apresentarem ou não um resultado material (Moraes Neto, 2006). Diferentemente, portanto, do que ocorreu com os prognósticos de Keynes, a análise de Marx, que não procurava fazer predições, especialmente de um momento histórico tão distante, acabou sendo muito mais feliz como antevisão histórica. Resta saber quais os desafios postos pela situação atual. Para o regime do capital, a pergunta seria: uma forma social fundada na produção mercantil com vistas à obtenção de lucro tem capacidade de proporcionar, de uma maneira geral, a conquista de um trabalho autorrealizador? A própria natureza da produção voltada para o lucro não dificultaria o processo por ela encetado de busca de um trabalho impregnado de sentido? Sem mencionar os efeitos perversos de uma crise econômica, como ilustra o momento atual, o que estamos querendo dizer é que o próprio regime do capital abre potencialidades, já vivenciadas, de uma vida mais rica, ligada a um trabalho "atraente", mas se transforma, ao mesmo tempo, num empecilho ao pleno desenvolvimento dessas potencialidades. Sendo assim, deparamo-nos com a ilustração histórica de uma noção marxiana de grande importância, a da contradição entre as forças produtivas e as relações de produção, amortecida durante a maior parte do século XX em função da forte presença da mediocridade taylorista-fordista. ${ }^{2}$ Parece-nos pertinente mencionar a presença dessa questão em textos anteriores:

${ }^{2}$ Em texto anterior, procuramos esclarecer esse "amortecimento": "A contraditoriedade do capital consigo mesmo está posta, por Marx, a partir do movimento de negação do trabalho vivo como unidade fundamental do processo de produção, e sua substituição pelo trabalho morto. Sendo assim, como se coloca a natureza auto-contraditória do capital quando sua base técnica possui a natureza taylorista/fordista? A resposta é: não se coloca; a forma taylorista/fordista de organizar o processo de trabalho não é contraditória com o capital enquanto relação social; pelo contrário, o taylorismo/fordismo chancela a
Através da explosão do taylorismo-fordismo, recoloca-se a questão enfatizada por Marx da prescindibilidade do trabalho vivo para a reprodução material da sociedade; a produção industrial passa a ser, em todos os seus segmentos, uma "aplicação tecnológica da ciência”. Para aqueles (poucos) que permanecerem com atividades de trabalho na área da produção material, tornarse-á possível superar a heteronomia do trabalho sob o capitalismo, permitindo um considerável grau de envolvimento do homem com sua atividade de trabalho (saliente-se que isto não supera a mediocridade social do capitalismo, coisa que se pode ilustrar, por exemplo, pela subordinação da segurança física dos trabalhadores ao cálculo do lucro em indústrias com elevado grau de risco). A questão que se coloca imediatamente é: e quanto à atividade de trabalho da grande maioria da população, que passará a ser dispensada do trabalho necessário à reprodução material da sociedade? Se a resposta da sociedade for um grande volume de desempregados, ela estará mostrando sua mediocridade; afinal, não haveria atividades socialmente úteis (e individualmente gratificantes) a desempenhar? A sociedade não necessitaria de atividades humanas nas áreas da educação, da saúde, das artes, da ciência, do lazer, etc.? Na verdade, a atividade humana será sempre socialmente imprescindível justamente onde é imprescindível a presença humana. Seria, dessa forma, possível estabelecer uma vinculação enriquecida entre trabalho e cidadania: as atividades de trabalho remanescentes seriam, a um só tempo, possibilitadoras do desenvolvimento das individualidades de quem as exerce, e do desenvolvimento da qualidade de vida de quem as usufrui. As relações de produção capitalistas permitem esse caminho histórico? A subordinação da produção de bens e serviços à lógica do lucro permite desenvolver o conjunto das atividades de trabalho enriquecedoras individual e socialmente? Não seria algo socialmente muito ambicioso para os limites estabelecidos pelas relações capitalistas? O que não é nada confortável para o capital é que as atividades de trabalho remanescentes dificilmente podem ser integralmente subordinadas à lógica capitalista da produção de bens e serviços como um meio para a valorização do valor. O capital defrontar-se-á com uma nova e difícil barreira, de natureza ética, caso queira subordinar todas essas atividades à lógica do lucro. Finalizando, por mais paradoxal que pareça, o atual momento histórico de fortalecimento do capitalismo pode estar gestando uma grande fraqueza, num futuro talvez não muito distante (Moraes Neto, 2003, p. 117-118).

forma social capitalista. Uma forma técnica lastreada no trabalho humano, que induz ao emprego de milhares de trabalhadores parciais/desqualificados, é perfeitamente assentada à forma social capitalista; o sonho da eternidade capitalista teria encontrado sua base técnica adequada" (Moraes Neto, 2003, p. 60-61). 
Este caminho de reflexão implica em considerar mais viva do que nunca a célebre advertência contida no Manifesto Comunista segundo a qual o capitalismo gera civilização demais para os estreitos limites colocados por sua mediocridade enquanto forma social (Moraes Neto, 2006, p. 59).

Alguns momentos dessa contradição fundamental aparecem nos dias atuais. Vejamos alguns comentários sobre palestra de Lawrence Summers no Forum Econômico Mundial, em Davos, Suíça, no dia 26 de janeiro de 2012:

"É uma ilusão que os iPods, iPads e Kindles vão criar mais empregos para pessoas normais", disse Summers. Para ele, a economia americana está evoluindo numa direção em que a criação de emprego terá de vir muito mais de segmentos ligados ao Estado, como saúde e educação, do que do industrial. [...] Os serviços de saúde, aliás, segundo Summers, são o segmento previsto para gerar mais empregos nos Estados Unidos nos próximos dez anos [...] O desafio da política econômica na atual fase do capitalismo, portanto, seria o de preservar o dinamismo dos setores de baixa criação de emprego que, por outro lado, produzem em massa bens de qualidade para a população, ao mesmo tempo em que tenta construir uma sociedade com trabalho digno para todos (Dantas, 2012).

Numa tentativa de "amarrar" as ideias imediatamente anteriores, vale questionar: se saúde e educação vierem a se constituir em fontes fundamentais de uso da capacidade humana de trabalho, como pensá-las como atividades inteiramente apropriadas pela lógica capitalista? ${ }^{3}$ Seria isso social e politicamente aceitável? Talvez essa dificuldade leve Summers a considerá-las como prioritariamente ligadas ao Estado. Seria, então, possível pensar num capitalismo com presença amplamente majoritária dos trabalhadores em setores não ligados à lógica capitalista?É o tratamento desses e de outros desafios contemporâneos ao regime do capital que vai fornecer significância à sua crítica.

Recebido para publicação em 27 de maio de 2013 Aceito em 18 de julho de 2013

Podemos estar em presenca daquilo que teria motivado o insight de Marx a respeito dos limites inerentes às atividades de serviços para sua apropriação pela lógica capitalista, infelizmente não explicitados pelo autor. (Moraes Neto, 2006).

\section{REFERÊNCIAS}

BECCHETTI, L. What is Wrong in Keynes's Prophecy? How the End of Economics Turned into the Rise of the Economics of Social Responsibility. In: PECCHI, L.; PIGA, G. Revisiting Keynes: Economic Possibilities for our Grandchildren. Cambridge, Massachusetts; London, England: The MIT Press, 2008.

BRYNJOLFSSON, E.; McAFEE. Race Against the Machine: How the Digital Revolution is Accelerating Innovation, Driving Productivity, and Irreversibly Transforming Employment and the Economy. Lexington, Masssachusetts: Digital Frontier Press, 2011.

DANTAS, F. Serviços ligados ao Estado serão fonte de emprego, diz economista. O Estado de São Paulo, 27 jan. 2012.

FREEMAN, B.M. Why do We Work More Than Keynes Expected? In: PECCHI, L.; PIGA, G. Revisiting Keynes: Economic Possibilities for our Grandchildren. Cambridge, Massachusetts; London, England: The MIT Press2008.

HOLZER, H.J.; LANE, J.I.; ROSENBLUM, D.B. ANDERSSON, F. Where Are All the Good Jobs Going? What National and Local Job Quality and Dynamics Mean for U.S. Workers. New York: Russell Sage Foundation, 2011.

KEYNES, J.M. 1930. Economic Possibilities for our Grandchildren. In: PECCHI, L.: PIGA, G. Revisiting Keynes: Economic Possibilities for our Grandchildren. Cambridge Massachusetts; London, England: The MIT Press, [1930] 2008.

LEVY, F.; MURNANE, R.J. The New Division of Labor: How Computers Are Creating the Next Job Market. New York: Russell Sage Foundation; Princeton,NJ; Princeton University Press, 2004.

MARX, K. Para a crítica da economia política (prefácio). São Paulo: Abril Cultural, 1974 (Os pensadores)

Elementos fundamentales para la crítica de la economia política - Grundrisse. México: Siglo Veintiuno Editores, 1978

economistas)

O Capital. São Paulo: Abril Cultural, 1983. (Os

MARX, K.; ENGELS, F. Manifesto do Partido Comunista. Textos, São Paulo, v.3, 1977. (Edições sociais).

Hucitec, $\overline{1991}$

A ideologia alemã. São Paulo: Editora

McKINSEY GLOBAL INSTITUTE. Manufacturing the Future: The Next Era of Global Growth and Innovation. [S.l.], 2012.

MORAES NETO, B.R. Marx, Taylor, Ford: as forças produtivas em discussão. São Paulo: Editora Brasiliense, 1989

Século XX e trabalho industrial: taylorismo/ fordismo, ohnoísmo e automação em debate. São Paulo: Xamã Editora, 2003.

. O percurso teórico da "abolição do trabalho" (ou da superação da "angústia smithiana”) em Marx: avancos e recuo. Revista da Sociedade Brasileira de Economia Política, Uberlândia,MG, SEP, n.14, jun. 2004.

Socialismo e forças produtivas: notas para o entendimento do novo. In: GALVÃO, Andréia et al. (Org.) Marxismo e socialismo no século 21. Campinas: CemarxIFCH-Unicamp/Xamã Editora, 2005.

Pós-fordismo e trabalho em Antonio Negri: um comentário. Revista da Sociedade Brasileira de Economia Política, Uberlândia, SEP n.18, jun. 2006. 
As forças produtivas em Marx e o surpreendente século XX. Revista de Economia, Curitiba, UFPR, v.34, n.especial, 2008.

MORETTI, E. The New Geography of Jobs. Boston; New York: Houghton Mifflin Harcourt, 2012.

NEGRI, A.; HARDT, M. Império. Rio de Janeiro;São Paulo: Editora Record, 2001.

NEGRI, A.; LAZZARATO, M. Trabalho imaterial. Rio de Janeiro: DP\&A Editora, 2001.

NOAH, T. The Great Divergence: America's Growing Inequality Crisis and What We Can do About It. New York: Bloomsbury Press, 2012.

PECCHI, L.; PIGA, G. (Ed.) Revisiting Keynes: Economic Possibilities for Our Grandchildren. Cambridge,
Massachusetts; London, England: The MIT Press, 2008. PHELPS, E.S. Corporatism and Keynes: His Philosophy of Growth. In: PECCHI, L.: PIGA, G. (Ed.) Revisiting Keynes: economic possibilities for our grandchildren. Cambridge Massachusetts; London: The MIT Press, 2008.

PRADO, E. Da posição e da deposição histórica do valor. In: ENCONTRO NACIONAL DE ECONOMIA POLÍTICA, 8., 2013, Belo Horizonte. Anais... Belo Horizonte: UFMG 2013

ROSDOLSKY, R. Genesis y estructura de El Capital de Marx. México: Siglo Veitiuno Editores, 1985.

ZILBERSHEID, U. The Marxian Idea of Abolition of Labor - Can it Be Reviewed? In: INTERNATIONAL CONFERENCE MARXISM 2000. Massachusetts: University of Massachusetts at Amherst, 2000. 


\section{EMPLOYMENT AND LABOR IN EARLY TWENTY-FIRST CENTURY: revisiting Keynes and Marx}

\author{
Benedito Rodrigues de Moraes Neto
}

The nature of labor in advanced economies has presented a significant change lately. The technological process has resulted in the reduction of labor without content and the expansion of labor with higher qualification or schooling, a phenomenon that can be discussed by turning to Keynes and Marx. As far as Keynes is concerned, his foresight was that technological progress would generate a huge reduction of labor time and the expansion of leisure time. Since this did not occur, the failure may be attributed to the fact of having worked with opposition between labor without content and leisure. Thus, it was not possible to capture the historical changes in labor and man's relationship with it. Marx's viewpoint is completely different, because his opposition takes place between labor without content and "activity labor", the latter impregnated with content and essential to the development of individualities. Therefore, present reality has a greater identification with Marx and presents major challenges to capitalism and its critique.

Key Words: Keynes. Marx. Employment. Labor. Technical progress.

\section{EMPLOI ET TRAVAIL AU DÉBUT DU XXIe SIECCLE: revisitant Keynes et Marx}

\author{
Benedito Rodrigues de Moraes Neto
}

La nature du travail dans les économies avancées a subi un changement récent important. Le progrès technologique a conduit à une réduction du travail sans contenu et à une augmentation de celui exigeant une plus grande qualification ou scolarité, phénomène qui exige la contribution de Keynes et de Marx pour en discuter. Dans le cas de Keynes, on peut mettre en évidence sa prévision d'un progrès technologique engendrant une immense réduction du temps de travail et une augmentation du temps des loisirs. Mais, considérant que cela n'a pas eu lieu, l'échec peut être attribué au fait de travailler en opposition avec le travail sans contenu et les loisirs, ce qui n'a pas permis de saisir les changements historiques dans le travail ni dans la relation de l'homme avec son travail. La vision de Marx est complètement différente puisque l'opposition qu'il fait est entre le travail dépourvu de contenu et le «travail activité », ce dernier étant imprégné de contenu et fondamental pour le développement des individualités. La réalité actuelle « combine » donc plus avec Marx et présente de nombreux défis pour le capitalisme et la critique qu'on en fait.

MotS-CLÉs: Keynes. Marx. Emploi. Travail. Progrès technique.

Benedito Rodrigues de Moraes Neto - Doutor em Ciências Econômicas. Professor adjunto (livre-docente) aposentado do Departamento de Economia da UNESP em Araraquara, SP. Atua principalmente em teoria e história dos processos de trabalho. Algumas publicações: Processo de trabalho e eficiência produtiva: Smith, Marx, Taylor e Lênin. Estudos Econômicos (USP.), v. 9, p. 651-671, 2009; O processo de trabalho em Marx e o surpreendente século XX. Revista de Economia, Curitiba, v. 34, p. 7-19, 2008; Marx, Taylor, Ford: as forças produtivas em discussão. São Paulo: Brasiliense, 1989; Século XX e trabalho industrial: taylorismo/fordismo, ohnoísmo e automação em debate. São Paulo: Xamã Editora, 2003. 